\title{
Whither 'high-tech' labor? Codification and (de-)skilling in automotive components value chains
}

DOI:

10.1016/j.geoforum.2017.11.023

\section{Document Version}

Accepted author manuscript

Link to publication record in Manchester Research Explorer

\section{Citation for published version (APA):}

Machacek, E., \& Hess, M. (2019). Whither 'high-tech' labor? Codification and (de-)skilling in automotive components value chains. Geoforum, 99, 287-295. https://doi.org/10.1016/j.geoforum.2017.11.023

\section{Published in:}

Geoforum

\section{Citing this paper}

Please note that where the full-text provided on Manchester Research Explorer is the Author Accepted Manuscript or Proof version this may differ from the final Published version. If citing, it is advised that you check and use the publisher's definitive version.

\section{General rights}

Copyright and moral rights for the publications made accessible in the Research Explorer are retained by the authors and/or other copyright owners and it is a condition of accessing publications that users recognise and abide by the legal requirements associated with these rights.

\section{Takedown policy}

If you believe that this document breaches copyright please refer to the University of Manchester's Takedown Procedures [http://man.ac.uk/04Y6Bo] or contact uml.scholarlycommunications@manchester.ac.uk providing relevant details, so we can investigate your claim.

\section{OPEN ACCESS}


3 Whither 'high-tech' labor? Codification and (de-)skilling in 4 automotive components value chains

Erika Machacek $^{\mathrm{a}, \mathrm{b},{ }^{*}}$ and Martin Hess ${ }^{\mathrm{c}}$

\section{Accepted for publication in GEOFORUM}

9

https://doi.org/10.1016/j.geoforum.2017.11.023

${ }^{a}$ Department of Geosciences and Natural Resource Management, University of Copenhagen, Øster

Voldgade 10, Copenhagen 1350, Denmark

${ }^{\mathrm{b}}$ Centre for Minerals and Materials (MiMa), Geological Survey of Denmark and Greenland, Øster

15 Voldgade 10, Copenhagen 1350, Denmark

'Department of Geography, School of Environment, Education and Development, University of Manchester, Arthur Lewis Building, Oxford Road, Manchester M13 9PL, UK

18 *Corresponding author at: Centre for Minerals and Materials, GEUS, Øster Voldgade 10, Copenhagen 1350, Denmark. Tel: +45 913338 62. Email address: em@ geus.dk 


\section{Abstract}

This paper seeks to address the limits of the global value chain (GVC) framework for explaining processes of deskilling in the changing international division of labor, outsourcing and offshoring. In the GVC framework, deskilling is insufficiently addressed in the context of social upgrading which usually focuses on measureable labor standards and enabling rights. Using a case study of component manufacturing in the automotive sector, this study shows that a critical understanding of the codification process is key for identifying how deskilling occurs within international divisions of labor in a high-tech industry. The paper draws on Michael Polanyi's conceptualization of tacit knowledge and Harry Braverman's work on labor and monopoly capital to refine and frame the role of codification in GVC governance structures. Currently, explanations of the ability to codify knowledge center on a technical and, at most, implicit experiential dimension of tacit knowledge (the know-how acquired through experience), and thus only on one of two constituents of Polanyi's conceptualization. Yet the cognitive dimension, which relies on the articulation and sharing of experiences, imitation, performance and other forms of knowledge exchange among workers, is largely absent. This is detrimental to explaining the complex processes of deskilling within GVCs. Empirically, our argument is illustrated by analyzing intra-firm decisions on codifying information for the manufacturing of automotive magnet components in Europe and in the magnet industry hub of Ningbo, China. Specifically, we discuss how these decisions liberate some workers in some places for skill upgrading (upskilling), but are clearly limiting many others to perform routine tasks removed from any innovative collaboration, i.e. (relative) deskilling. The paper finds an international division of labor facilitated and maintained to no small extent by intra-firm decision-making on knowledge codification, with mixed results for skills upgrading and (relative) deskilling.

\section{Introduction}

The contemporary global economy is characterized by highly fragmented production processes as a result of capitalist dynamics to reduce cost and increase flexibility as well as speed. To achieve this, capital is constantly looking for new spatial, technological and organizational fixes (Coe and Yeung 2015: 4ff.) and thus continuously transforming Global Value Chains (GVCs) and Global Production Networks (GPNs). Developing new divisions of labor through outsourcing and offshoring is enabled to a large extent by the ability to share and codify information. Information flows and technological development are central to an understanding of codification, namely the process of articulating and standardizing information, which determine any given transaction, including that of a buyer and supplier, which is often the central focus of analysis in GVC analysis. But 
1 technological development can impair labor skills, such as when automation processes

2 facilitate deskilling, including robots taking on low-paid tasks, making labor redundant in 3 some types of manufacturing (Zuboff 1988) on what Peck (2017) calls 'the road to

4 Robotistan'. Automation obviously requires codification: Only codifiable processes can

5 be transferred easily across organizational and geographical space and without significant

6 personal interaction between one worker and another. This codification in turn relies on

7 the articulation and standardization of information and facilitates access to cheap labor

8 pools via labor arbitrage. In this paper, we argue that codification is an antecedent to

9 deskilling, as codification enables the separation of work processes into transmissible 10 parts that can easily be outsourced. This in turn enables work processes to be executed by 11 a labor force that does not require specific or additional training, and as such codification 12 not only enables the spatial disintegration of work processes but also has significant 13 implications for skills development and upgrading in the various places connected by 14 GVCs and outsourcing networks.

15 In essence, codification enables a process of deskilling as it significantly limits jobrelated personal interaction in the outsourcing process and, arguably, codification creates 17 a dynamic in information flows that effectively prevents a substantial part of the workforce from the possibility of upskilling. The work processes of such a 'deskilled' part of the workforce are routinized and the workers become marginalized / reduced to the simple execution of tasks according to codified processes, while some other workers may be freed for upskilling, involving conceptual stages of work such as designing components. These processes already have received some attention in the GVC framework and governance typology as developed by Gereffi, Humphrey and Sturgeon (2005), and elaborated on in the subsequent section. However, it has been barely discussed how the ability to codify information affects processes of acquiring know-how and experience by workers, their articulation and sharing of experiences, and opportunities for learning, imitation and performance. In other words, the comprehensive role of tacit knowledge (Polanyi 1966) has been neglected to some extent, given its centrality for organizational decision-making regarding outsourcing and the division of 30 labor. 
1 Importantly, it remains to be unpacked how the ability to codify informs processes of deskilling under monopoly capital (Braverman 1974). In general, deskilling is hardly addressed in the GVC literature. Rather, the focus has been on the social upgrading of workers, usually defined as improving working conditions (measurable rights) and enabling rights such as collective bargaining and freedom of association (Barrientos and Smith 2007; Barrientos et al. 2010; Barrientos, Gereffi and Rossi 2012; Elliot and Freeman 2003; Tokatli 2013). Social upgrading is often assumed to automatically follow economic upgrading, namely when firms enter in higher value production or reposition themselves in GVCs (Knorringa and Pegler 2006); but the relation between social and economic upgrading is not always straight forward (for example, see Lee, Gereffi and Barrientos 2011; Rossi 2011).

In this paper, we argue that an analysis of the ability to codify information and knowledge sheds new light on processes that affect the nature and quality of work, and illuminates codification as a necessary precondition for deskilling in GVCs. With an empirical case on codification in automotive component manufacturing, this paper attempts to demonstrate how codification enables an international division of labor that while positioning some workers for upskilling - leads to substantial deskilling for others. More specifically, we argue that understanding the knowledge codification process as a precursor to deskilling is key for identifying how and where deskilling occurs within the international division of labor. We also address the question of how the codification process shapes the creation and reproduction of higher-skilled and lower-skilled labor. Thus we aim to make three contributions to the literature:

- First, mobilising both Polanyi's (1966) work on tacit knowledge and Braverman's (1974) seminal text on labour and deskilling, we push for a more nuanced understanding of social upgrading in GVCs and GPNs.

- Second, we demonstrate the continued relevance of labor arbitrage and deskilling (cf. Peck 2017; Previtali and Fagiani 2015) while recognizing the potential for selective upskilling and social upgrading.

- Third, the paper empirically illustrates processes of codification and (relative) deskilling in a high-tech industry usually seen as exemplary for both economic and social upgrading. 
1 In what follows, and drawing on Michael Polanyi's cognitive dimension in his conceptualization of tacit knowledge, we explore codification practices in automotive component manufacturing to argue that codification is crucial for enabling a rather clearcut division of labor where upgrading/upskilling is possible for some jobs while many others are affected by deskilling as tasks are fulfilled that rely on prior codification of information, and over time are at risk to be made redundant by automation. The paper is structured as follows: Following this introduction, section 2 develops the conceptual and analytical arguments. Section 3 then outlines the methodology, followed by the analysis of findings from the empirical case study in section 4. Section 5 concludes with reflections on the wider implications of the findings for both empirical and conceptual research.

\section{Governance, codification and skills in GVCs and GPNs}

In its early formulations, the 'New International Division of Labor' (NIDL) thesis emphasized the emerging functional division between high labor cost regions where multinational corporations performed core activities while relocating more standardized, labor-intensive tasks to low wage countries (Coe and Hess 2012; Froebel, Heinrichs and Kreye 1981; Massey 1984; Starosta 2016). As Massey (1984: 3) argued, however, the spatial division of labor is not so much about a geography of jobs alone but about powerinfused social relations that span across the globe and represent new spatial forms of social relations and socio-economic organization.

Global industrial restructuring has been the focus of the NIDL literature where offshoring of production is argued to occur because of anticipated benefits of "low-cost, relatively docile labor in the periphery" (Schoenberger 1988: 106). The NIDL emphasizes the changes in spatially distributed functions in the global economy as opposed to a broader sectoral and horizontal division of labor, and a core-periphery dualism based on unequal trade relationships where the core exports manufactured goods and the periphery serves as the source of raw materials and commodities (cf. Hopkins and Wallerstein 1977; Lipietz 1985). High-level knowledge and skill-intensive activities are then tied to the core, while standardized, low-skilled production processes are decentralized in the periphery. Importantly, the NIDL model "foresees a continued shift of standardized production processes to less developed areas" (Schoenberger 1988: 106). Today, the 
1 picture of course is much more complex than what the NIDL thesis described, and new analytical frameworks were developed to grasp the increasing complexity of global economic networks, notably global commodity chain, global value chain and global

4 production network analysis (Coe and Yeung 2015; Gereffi and Korzeniewicz 1994;

5 Gereffi et al. 2001; Henderson et al. 2002;)

6 Among these network approaches, the GVC framework developed a specific typology of governance structures that moved beyond the earlier notions of producer- and buyer-

8 driven commodity chains to reflect the growing complexity of inter-firm relations in 9 global value chains and production networks (Gereffi, Humphrey and Sturgeon 2005). 10 The GVC framework in particular enabled a systematic approach to analyzing the nature of firms' linkages with buyers and suppliers and their related governance forms. These governance structures are at the heart of the GVC framework and are derived from analyzing transactions between buyers and suppliers at the segments of the GVC by means of exploring the underlying characteristics of the transactions. Three variables have been defined to delineate and analyze the transactions: the ability to codify a transaction, the complexity of the transaction, and the capability of the supplier. Each of these variables is allocated a high or low value during the analysis (see Table 1), which results in five empirically demonstrated governance structures: Market and hierarchy governance at the extreme ends, whereby the transactions of the former are governed solely by price, and those of the latter are intrafirm transactions, following an acquisition of a supplier/buyer.

Table 1. Governance variables and the degree of explicit coordination and power asymmetry

\begin{tabular}{lllll}
$\begin{array}{l}\text { Governance } \\
\text { type }\end{array}$ & $\begin{array}{l}\text { Complexity } \\
\text { of transaction }\end{array}$ & $\begin{array}{l}\text { Ability } \\
\text { to codify } \\
\text { transactions }\end{array}$ & $\begin{array}{l}\text { Capabilities } \\
\text { in the supply-base }\end{array}$ & $\begin{array}{l}\text { Degree of explicit } \\
\text { coordination and power } \\
\text { asymmetry }\end{array}$ \\
\hline Market & Low & High & High & Low \\
Modular & High & High & High & I \\
Relational & High & Low & High & I \\
Captive & High & High & Low & I \\
Hierarchy & High & Low & Low & High \\
\hline
\end{tabular}

Source: modified after Gereffi, Humphrey and Sturgeon 2005: 87. 
1 These processes relate to increasing international trade in components; from 'trade in goods' to 'trade in value-added' and 'trade in tasks' (Gereffi and Lee 2012), and augmenting complexity in coordination forms as the production processes for a single end-product is dispersed across different countries and continents. Apart from the ideal types of 'pure' market relations and complete hierarchy there are three networked forms of governance relevant for coordinating inter-firm relations, namely modular, relational and captive governance structures. These are characterized by transactions in which the exchange of information is central, in addition to the price. Relatively little power disparities mark the transactions between the buyer and the supplier in these governance structures. In practice, this reflects a more equal split of abilities between the buyer and supplier as they coordinate their transaction. Nuances in these networked governance forms pertain to the stronger reliance on standards in modular governance, the intense information exchange in relational governance, and more buyer-driven coordination in the captive governance forms. For our analysis, a firm's ability to codify transactions and the role of tacit knowledge are of particular concern, as they directly relate to questions of upgrading and skills.

\subsection{Codification and tacit knowledge in the value chain}

Codification can be conceptualized as a process that involves the preparation of information in order to enable its transmission, as denoted by Gereffi, Humphrey and Sturgeon (2005: 85):

"The complexity of information transmitted between firms can be reduced through the adoption of technical standards that codify information and allow clean handoffs between trading partners. (...) When standards for the hand-off of codified specifications are widely known, the value chain gains many of the advantages that have been identified in the realm of modular product design, especially the conservation of human effort through the re-use of system elements - or modules - as new products are brought on-stream (Robertson and Langlois 1995; Schilling and Steensma 2001; Sturgeon 2002)."

Despite the dynamics of the seemingly easy linking and de-linking of suppliers and customers which are organized in 'a very fluid and flexible network structure', considerable flows of non-price information occur in codified form at the inter-firm 
boundary, which provide the argument for governance structures other than the market, namely for instance modular governance (Gereffi, Humphrey and Sturgeon, 2005: 85). While the reduction in the complexity of transactions by means of codification constitute one overall set of coordination challenges to overcome, the other set of challenges concerns the integration of new suppliers into GVCs. This latter challenge involves balancing capabilities, including for production that is to meet requirements of the domestic market and export markets. This augments the need for 'monitoring and control' by the buyer (Gereffi, Humphrey and Sturgeon, 2005: 85; see also Coe and Yeung 2015 for a fuller discussion of the cost-capability relationships in global production networks).

As shown in Table 1, three variables justify five governance structures in the GVC framework. The low 'ability to codify transactions' sets the relational form apart from modular governance and from the captive network form. In addition, the captive form shows relatively low capabilities in the supply base. However, we argue that tacit knowledge is not fully conceptualized in the GVC governance typologies. The three variables seem to center on a technical and, at most implicit, experiential dimension of tacit knowledge (the know-how acquired through experience), i.e. one of two constituents of Michael Polanyi's (1966) conceptualization of tacit knowledge. Yet the cognitive dimension, which relies on articulation and the sharing of experiences, imitation, and performance, is largely absent. This is despite the GVC governance typology's justification of relational networks by drawing on Williamson's (1981) definition of 'human assets' through bounded rationality and human skills. These human skills are understood as 'learning by doing', which aligns with Polanyi's experiential dimension of tacit knowledge. It is particularly surprising that the argument for relational governance, Williamson's (1983) 'credible commitments' which describe the act of safeguarding a relationship through an exchange, especially when contracts do not capture the complete dimension of the exchange, has not been further explored.

We argue that this is detrimental for two reasons: (1) it excludes the full range of human knowledge active in intra-and inter-firm exchanges, including those enabled by codification, and (2) it inhibits a comprehensive understanding of the role of information exchange and human knowledge in deskilling. Specifically, we argue that the current 
1 definition of the 'ability to codify' variable insufficiently addresses the potency of

2 codification for deskilling. This is despite its operationability at the boundary of codified information and tacit knowledge. As Gertler (2003: 78) notes, "the tacit component of the knowledge required for successful performance of a skill is that which defies codification or articulation - either because the performer herself is not fully conscious of all the 'secrets' of successful performance or because the codes of language are not well enough developed to permit clear explication".

Michael Polanyi's (1966) notion of the tacit dimension is often summarized as "(...) we can know more than we can tell." He uses the example of knowing a person's face: We are able to recognize it among many, without being able to tell how we do that. New police methods helped to communicate this knowledge by providing a range of facial features. Nonetheless, we cannot tell how we compile these features. Polanyi (1966: 6) draws on Gestalt psychology, yet not as impressed perceptions of a physiognomy on the retina or on the brain but as "the outcome of an active shaping of experience performed in the pursuit of knowledge". He conceptualizes our inability of specifying elementary movements that serve to achieve a joint purpose, as we shift attention from the elementary acts to the achievement. On the example of a blind man feeling his way by tapping with a stick, he also describes "how an interpretative effort transposes meaningless feelings into meaningful ones (...)” (Polanyi, 1966: 13). These conceptualizations allude to the experiential and cognitive dimension of tacit knowledge that codification cannot capture, with consequences for upgrading and skills.

\subsection{Upgrading and skills}

In this paper we claim that the ability to codify knowledge, in the context of the complexity of transactions and the capability in the supply base, can shed new light on processes of deskilling, emphasizing codification as an antecedent to deskilling. To date, deskilling is hardly addressed in the literature on GVCs, if only remotely touched upon in the context of social upgrading.

Economic, or "industrial upgrading", or simply "upgrading", is a clear focus in GVC research and emphasizes a producer's ability "to make better products, to make products more efficiently, or to move into more skilled activities" (Pietrobelli and Rabellotti 2006: 
1 1). Technological sophistication and value-added are at the center-stage of this upgrading 2 discourse, and Humphrey (2004) and Humphrey and Schmitz (2002) have specified four types of economic upgrading: process-, product-, functional and inter-sectoral upgrading. Specifically, upgrading in the GVC literature is explained as 'a move up' in the value chain which is tied to "more rewarding functional positions" or by making more valueadded products with prospects of higher returns (Gibbon and Ponte, 2005: 87-88).

The term 'upgrading' in GVC literature describes relative improvements of the positioning of a firm within the GVC in anticipation of benefits, such as in form of opportunities of adding higher-value to a product. The upgrading concept is concerned about delineating the acquisition of capabilities and the access to new market segments through participation in particular GVCs. In their earlier version of network, quasihierarchy, hierarchy, and market governance types, Humphrey and Schmitz (2002) argue that the type of governance dynamics at play in a particular GVC influences the possibilities available for upgrading. In principle, an exploration of 'upgrading' seeks to provide answers to two questions. One question refers to skills, competences and supporting services required to enter the GVC. The other question addresses the pathways available to developing countries regarding the transformation of linkages in the GVC for upgrading that benefits their societies, firms and industries (Gereffi et al. 2001) not only economically, but also in terms of social upgrading.

The notion of 'social upgrading' has been increasingly problematized in the literature (for a critical overview, see Selwyn 2013). This work is concerned with unveiling enabling rights, the extent of collective bargaining and freedom of association, and measurable standards including benefits and wages (cf. Tokatli 2013). However, the 'upgrading literature's noticeable silence on the ability of labour to win concessions from capital has been criticized by authors such as Selwyn (2011) and Coe and Jordhus-Lier (2010). Coe and Jordhus-Lier (2010: 221) are adamant that the upgrading literature has to at least acknowledge that 'some workers have the agency to improve their relative position', and in a similar vein Tokatli (2013: 996) suggests that 'a thorough incorporation of the concept of labour agency into the upgrading literature' is required.

More recently, the GVC and GPN literatures have made the case that economic and 
1 Knorringa and Pegler 2006), and scholarly work has attempted to connect these two

2 dimensions of upgrading for example by examining how they are measured in GPNs (cf.

3 Milberg and Winkler 2011). These attempts of connecting economic and social upgrading

4 coincided with the elaboration of typologies of work, namely low-skilled, labor-intensive

5 work (Barboza and Tabuchi 2010; Barrientos, Gereffi and Rossi 2012; Gereffi 2009;

6 Zeng 2010), and medium-skilled, mixed production technologies work (Barrientos,

7 Gereffi and Rossi 2012). It is this Taylorist separation of conception and execution, one

8 of the central tenets upon which Braverman's (1974) deskilling thesis was founded, that

9 is of particular concern here (see also Jha and Chakraborty 2014 for the case of Indian automotive GPNs). As Streek (2005: 261) puts it, Braverman developed the argument that “ $[\mathrm{by}]$ 'deskilling' manual work, and 'degrading' work in general, employers take the management of production away from the workers, and with it the value it creates. As the latter is appropriated by employers - or allocated in part to a factory hierarchy of professional managers loyal to the employer-the rate of exploitation increases (Braverman 1974).”

The employment relationship as central institution of the labor market, broadly speaking, experienced a shift in 'industrial society', from 'contracts of work' to 'contracts of employment', starting with early industrialization and continuing well into the decades after World War II when Harry Braverman wrote his seminal text. In the former, the labor supply is skilled as work includes conception and execution, in the latter, work is deskilled, as conception and execution are separated. This shift in the employment relationship marked a significant change from 'integration to separation of conception and execution' (Streek, 2005: 260), or as Sørensen (1994) put it, from market coordination to coordination by organizational incentives inside firms. Along this line of argument, tasks performed by labor at the shop floor level — if not made expendable outright by technological advancement - are less complex and narrower in range, with an associated reduction in both cost and bargaining power.

In this context, the advancement of technology plays a significant role: With regard to computerized machine tools, the conceptual component of work constitutes programming, with execution denoting operation and equipment supervision (Whittaker, 1990). As we show later, the conceptual component of work in our case study can be 
1 taken to mean magnet design and specification, while execution might refer to the work

2 of labor in operating the manufacturing machines. To the extent that the ability to design and manufacture relatively advanced magnets is embodied in tier two (T2) suppliers ${ }^{1}$, in

4 the form of skills and knowledge, and some of this knowledge is being codified for 5 manufacturing by T3 suppliers, it is the latter for whom discretion over the work process 6 is wrested. In such a scenario, as we will subsequently elaborate, evidence of a spatial 7 division of labor along skill and technological lines is potentially perpetuated. As a consequence, and echoing Peck's (2017) comprehensive analysis of the global outsourcing complex, what is being created and reproduced is an economic landscape where we find 'routinization and deskilling; competitive disciplining of onshore and offshore labor [... and] islands of offshore upskilling in an ocean of deskilling' (Peck 2017: 205). In other words, codification of knowledge and information continuously transforms outsourcing and inter-firm relationships and leads to complex, ever changing processes of social upgrading and downgrading, skills upgrading and deskilling in the various places connected by GVCs and GPNs.

\section{Methodology and data}

Using the empirical case of European rare earth elements (REE) magnet manufacturers which are on the one hand in competition with third-tier (T3) Chinese suppliers and on the other hand aspire to come into closer collaboration with first-tier (T1) suppliers to the car manufacturers, we explore how codification is executed. This case illustrates processes of codification and points at the relevance of tracing information flows to provide a more nuanced view on intra- and inter-firm coordination, and its effects on (relative) deskilling.

The research generated a dataset comprising of 54 interviews which were conducted with firms operating along the GVC of REE magnets (such as REE-exploration firms, chemical separators, metal alloy producers, magnet powder producers, magnet manufacturers, traders of final magnets, and T1 suppliers to the automotive industry as well as REE-magnet end-users in the wind energy sector). Here we draw specifically on interviews conducted with magnet manufacturers across the EU and in Ningbo, China,

\footnotetext{
${ }^{1} \mathrm{~A}$ tier two (T2) supplier is situated at the second level in a supply relationship with a buyer. For example, a T2 supplier might supply components to a $\mathrm{T} 1$ supplier who then assembles these components into a final product which in turn is sold by the T1 supplier to the end-user (car manufacturer).
} 
from May 2013 to March 2014, to explore their exchanges with buyers and suppliers of magnets, and to establish codification routines.

3 In conversations with respondents, mostly from national industry associations for the magnet manufacturers in the EU, a sampling frame was produced identifying EU-based rare earth magnet manufacturers. Desktop research was then used to determine whether the firms listed in the sampling frame indeed manufactured REE-magnets. This resulted in a total of 11 representatives of 11 European injection bonded REE-magnet manufacturers and four representatives of two European based sintered REE-magnet manufacturers. The former account for almost two thirds of European REE-magnet manufacturers using injection-bonding as production technology. This injection-bonding magnet market size calculation is based on the 11 firms and additional four firms in Italy, and one firm each in France and Romania, which are not included here, as it was not possible to collect data from them. Respondents have been anonymized and given codes, indicating the location of the manufacturer (' $\mathrm{N}$ ' for Northern Europe, 'W' for Western Europe, and ' $\mathrm{C}$ ' for Central Europe), followed by ' 1 ' for interviews at CEO or managing director level or ' 2 ' for middle management interviewees, e.g. head of department, and then ' $a$ ' to ' $d$ ' indicating a specific company. The decision to anonymize the specific location of the manufacturer and refer only to a geographic region serves to point to observed regional differences in the involvement in manufacturing processes, specifically to elucidate nuances including for future research. Overall, the sorting enabled a dissection and identification of codification procedures and routines with the aim of linking these procedures and routines to effects for labor processes along the value chain. Specifically, the data served to examine how codification affects the skill-set of laborers in a spatial division of labor.

In contrast, data from manufacturers in China were collected using purposive sampling in the city of Ningbo, a prominent hub for the Chinese magnet industry, during the International Conference on $\mathrm{NdFeB}$ Magnets in the city and including interviews with three REE-magnet manufacturing firms at their booths at the conference, while one interview took place at the company premises during a factory visit. These firms are renowned for their technological leadership in China and their collaboration with European magnet manufacturers. This collaboration was confirmed in the interviews with 
1 the REE-magnet manufacturers in the EU. In-depth interviews with several

2 representatives of one magnet manufacturer were facilitated by a translator during a visit

3 of the factory in Ningbo. The personal, guided tour through the factory was insightful to

4 provide additional insights into the labor processes accompanying the manufacturing

5 technology. In the following section, we now turn to the analysis.

\section{Codification and deskilling in component manufacturing}

7 European bonded REE magnet manufacturers are medium-sized firms with several

8 hundred employees. Manufacturers produce about 70 to 200 million pieces of customized magnets per year for different series and serve numerous industries and niche markets, yet their largest customers are found in the automotive industry where demand for magnets is growing as cars are further 'electronified'. The augmenting electronification is tied to the use of small motors in which magnets carry out key functions.

The methods to manufacture the magnet can be divided into sintering and bonding. A differentiation of these two main manufacturing methods and its sub-categories is essential for our analysis as the resulting magnets are used in different applications and the firms applying these technologies show different industrial development trajectories. The European magnet manufacturing landscape is home to only one large, integrated firm in the sintering technology, yet numerous firms that use the bonding technology. This latter technology is the focus of the analysis as its two methods of compression and injection exhibit different development trajectories that we trace to exemplify a spatial division of labor enabled by codification which we claim is tied to deskilling.

Sintering refers to the process of compacting and forming a solid mass of material by pressing or heating it without melting it to the point of liquefaction. Bonding refers to the tying of the magnet material by using two different methods, namely compression or injection. In the former, the magnet material is pressed into a form and needs to harden, thus the manufacturing follows a two-step process, while in the latter the material is injected into a form in a one-step process. The advantages of injection-bonding as compared to compression-bonding lie in the wide variety of magnet shapes that are enabled, as the material is injected. This offers ample opportunities for new designs of magnets and the applications in which the magnets are to perform a function, as a magnet is never used on its own, but in an assembly as a component to perform a particular task. 
1 A magnet could for instance feature in the main motor of a car, but also in a seat 2 adjustment motor, or in window motors. However, while from a pure magnetic performance point of view the compression-bonded magnet is preferable, the appeal of

4 this technology is weakened by limited geometric variability ${ }^{2}$.

Figure 1. Manufacturing segments for bonded magnets.

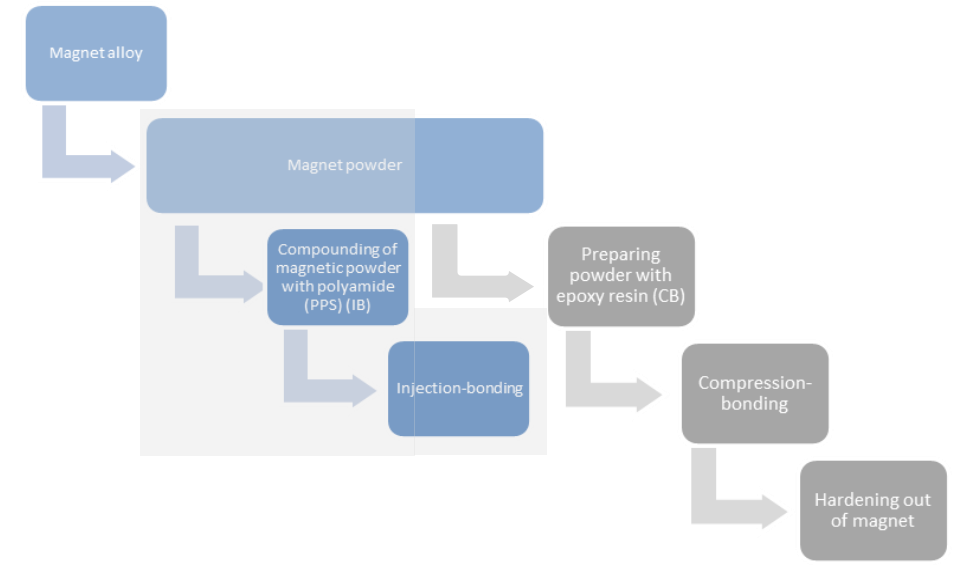

Source: authors.

Note: The analysis presented here focuses on the highlighted injection-bonding processing segments only.

Labor is needed in all the processes depicted in Figure 1, and skills are acquired through learning-by-doing in the magnet manufacturing process segments, and are, depending on the number of processes hosted in-house, connected to knowledge about: (i) how to break the magnet alloy; (ii) how to coat the powder (epoxy) for compression-bonding, or (iii) how to melt the polyamide to insert the magnetic powder and make a compound which is then introduced into the injection-bonding machine. Furthermore, the necessary skills and knowledge base is connected to magnet assembly, magnetizing and magnet handling, and testing magnet qualities. In the following analysis we lay out the types of knowledge and labor needed to accomplish the processing.

The first concern of European magnet manufacturers is related to the handling of their material input for manufacturing, the metal powder. This requires a particular knowledge

\footnotetext{
${ }^{2}$ Limited geometric variability refers to the restrictions in the geometric shapes of a final magnet made with this technology, namely simple forms such as squares, circles and a few other shapes into which magnet powder is filled to be bonded by compression.
} 
1 that can be aligned to the experiential dimension of knowledge (Polanyi 1966): "Anytime 2 you have a finely divided metal powder, it's gonna be somewhat reactive to air. (...) We

3 built a lot of infrastructure to keep the powder under argon at all times. One of the things

4 that you see happening when you process a material is that the amount of oxygen it will

5 absorb from one day to the next isn't ever exactly the same (C1a)." Seasonal differences

6 that affect the output of magnets have also been noted, and it becomes clear that

7 knowledge acquired over time in the handling of the purchased input of magnet powder

8 has implications for the manufacturing and the quality of the final magnet. This

9 knowledge does not exist in codified form for transmission to other industry participants;

10 the manufacturers might know more than they can tell, while they may be able to

11 communicate some of their knowledge that they acquired through learning-by-doing. In

12 essence, the worker will need to have an understanding of the variability of oxygen

13 absorption by the magnet material over time and the worker will need to be able to monitor changes and adjust for them to ensure a consistent quality of material input into the manufacturing process.

\subsection{Process integration versus codification}

Processes preceding the injection bonding method that originally were handled externally and precede the actual magnet manufacturing, such as the manufacturing of tools and compounding of the magnet material, were integrated by European manufacturers amid fierce competition from Chinese manufacturers. This integration enabled the European players to build on already present in-house skills and capabilities: "We started to injection mould magnets somewhere around late 1980s. You know, we have been moulding magnets for a very long time and we are still moulding the same magnets as we did at the time (N1a)." Tools are made that are fitted on the injection-bonding machines, each of which can carry numerous tools. These tools will hold the magnet compound when it is injected and gives shape to the magnet. A European magnet manufacturer summarized what the buyers of magnets actually buy when they place an order: "Customers order tools and automation (C1b)."

For every customer a new compound is made. Thus, compounding is a highly customized process: The worker compounds (mixes) purchased base material, not just with polyamide but also with other materials, e.g. $90 \%$ rare earths (including neodymium) and 
15 to $10 \%$ of a secret recipe $(\mathrm{C} 1 \mathrm{~b})$. In addition, the integration of these processes in-house enabled the manufacturers to protect knowledge internally, which was considered preferential to for instance patenting: "The advantage of the [magnet] material is the compound and we don't patent compounds because if you patent compounds, you put the way you are making your compound [forward to competitors], [by providing insights on compounding] you're now [placing competitors] in the reach [of] the big knowledge. So, all our compounds are not patented. So, it's impossible to know what it is inside. Even us, we don't know exactly what is inside (W1a)." This illustrates what Polanyi (1966: 5) described as the "very act of communication [which] displays a knowledge that we cannot tell". Arguably this specific context reflects a cognitive dimension which relies on articulation and the sharing of experiences, imitation, performance and other factors in tacit knowledge creation.

While it has been mentioned by interviewees that standard grades of compounds are preferred in the manufacturing process, several manufacturers pointed out that it depends on the characteristics that the customer would like the magnet to fulfil, as to whether the magnet material (compound) used will need to be changed, e.g. from the most commonly used 'B powder' of Magnequench (the largest supplier of the powders), to a compound prepared by a Japanese firm which uses the Magnequench powder as basis, e.g. " $60 \%$ of the powder and $40 \%$ of the polyamide. In some cases it's $80 \%$ of the powder, $20 \%$ polyamide (N1a)."

\subsection{Codification routines}

European rare-earth magnet manufacturers are generally second-tier (T2) suppliers to the automotive industry: they compete with their third-tier (T3) Chinese suppliers and are endeavoring to obtain a favorable position with $\mathrm{T} 1$ suppliers to automotive industry endusers, which is considered to bring about advantages with regards to stability in the supplier-buyer relationship, and closer access to more creative, innovative work that is generally tied to higher value-added products.

Transactions between T2 magnet manufacturers, their T1 buyers and Chinese T3 magnet manufacturing suppliers in the automotive industry are characterized by routines that concern: (i) the codification of the quality standards of the magnetic materials used for magnet production (as specified in the IEC 60404 series); (ii) the development of a 
management system aimed at continual improvement, emphasizing defect prevention and the reduction of variation and waste in the automotive industry supply chain (as specified by ISO TS 16949); and (iii) how the magnet is to function in a system module (as opposed to how the magnet is to be made). When examining the above points, specific skill requirements of the workers come to the forefront: Regarding the first point material quality standards, the worker at the EU-based magnet manufacturer needs to have an understanding of the firm-internal standards for a material as the worker qualifies the material in a standardization process. In addition, the worker needs to understand application-specific tests:

"We have to basically qualify a material which is equivalent of our standards for a material. This is of course only once - then there is this material. For each product we do indeed produce custom parts, we would have to drive the application-specific tests. (...) And because the material typically goes into 20 to 30 items, we would have to go through such a release procedure about 20 or 30 times. That is extremely complicated and then you have indeed in each item in the area another 50,000 EUR for releases $(\mathrm{C} 1 \mathrm{c}) . "$

Moving on from the magnet powder to the processing methods where differences pertain to the type of technology applied, a clear geographical difference becomes apparent. Here, the value chain ties between the European and Chinese manufacturers are at centerstage as these have been pointed out by all European manufacturers as important to their business, in the context of the growing significance of Chinese magnet manufacturing of sintered and compression bonded permanent magnets, and including lower unit-costs of magnets enabled by low labor costs and local access to the raw materials.

Over time, European manufacturers prioritized the injection-bonding method which enables technological advances over compression bonding which constitutes the major bonding method applied by Chinese manufacturers. This prioritization occurred for several reasons: European manufacturers needed to cut costs and improve competitiveness amid large magnet volume manufacturing in China which turned to softpressing as an alternative way of compression bonding and has been described as highly cost-competitive: "Soft-pressing is very much the standard Chinese approach and...there are reasons for that but the number one reason is that it's very labour-intensive which is 
why they do it and why we don't. Now the material you get out of it is generally pretty good, it's not the very best possible but it's 99\% of the way there (C1a)." With the softpressing technology, significantly more labour needs to be put in the work flow: The worker is required to carry out numerous tasks by hand in China, in what is described as a 'moderate press' process in which one press follows another press, for example an isostatic press followed by a tool-press. Manufacturers in Europe used one technology type for pressing only, in a one-step process from loose powder to grain density (C1a). It was no longer justifiable to manufacture compression-bonded-magnets in Europe if Chinese suppliers were able to manufacture these at nearly the same quality and at a lower cost:

"if you don't mind putting labour in and doing a lot of things by hand, it's [soft pressing] a perfectly valid process. Whereas for us, when we press a magnet out, when I mount it up on a tool press or a hydraulic press, I take it all the way to grain density. I don't do this moderate press where I then have to press it again later (...) either I isostatic press or I tool-press it and for us, it has to do with the properties of the material and cost of labour. (...) So, because our labour base is different than the Chinese, we apply different technologies than they do (C1a)."

The European magnet manufacturer emphasized that 'different cost for the space, for the equipment' are additional reasons for using different technologies. Challenges encountered by a European manufacturer who attempted to introduce 'western technology' to China in its joint venture were summarized as follows: "The machines wouldn't do what I needed them to do. The people wouldn't be trained to do it. And then, the advantage to them to do it my way versus their way really doesn't make it worth the time. When you can simply do the same thing everyone else [ref. to European manufacturers with joint ventures] in China does - pay them and call it a day and be very, very competitive (C1a)."

This explains the motivation of European manufacturers to maintain supply relationships with their Chinese suppliers: the former offer a one-stop-shop service to the buyers of magnets who are T1-suppliers in the automotive industry. These T1 firms provide technical specifications for the magnets in design files, which they own, to the T2 magnet manufactures. They are interested in sourcing both compression and injection-bonded 
1 magnets, which compelled the European manufacturers to offer a one-stop-shop service,

2 selling both sintered and compression bonded magnets that they source from their

3 Chinese suppliers, and injection-bonded magnets which they manufacture in-house. Such

4 a product portfolio requires detailed technical knowledge by the employees and workers,

5 as they need to translate customer needs (of the $\mathrm{T} 1$ buyer) expressed in quality

6 performance standards into tangible magnets. The product portfolio offer has several

7 advantages for the European manufacturer.

8 Most importantly, the outsourcing of compression-bonded magnet manufacturing to the

9 Chinese manufacturer frees the labor force of the European magnet manufacturer up to 10 focus on advanced, geometrically diverse magnets made with injection-bonding 11 technology. This involves a focus on the conceptual stage of designing the magnet, including in collaboration with the T1-buyer, which at times might also include the final customer (car manufacturer). This development constitutes skill upgrading (upskilling) for the European manufacturer: A close working relationship with the T1-buyer, as a onestop-shop supplier, with the added advantage provided by its focus on a superior manufacturing technology enables the European manufacturer to be positioned as a supplier that may be invited in co-design development rounds of future magnets.

The Chinese manufacturer in Ningbo, in contrast, continues to use established manufacturing technology when making magnets for the European manufacturer. For the skill requirements of the laborer at the Chinese factory, the upgrading of the EU-based manufacturer implies that the level of skills required from Chinese laborers remains static and needs to be nurtured to be at least maintained, as explored above in the context of soft-pressing technology. These skills involve operating the machines, for example filling the machinery with magnet material, and monitoring the magnet output, such as by visually examining whether these meet the expected criteria of size and thickness. 26 Surprisingly, checks for a deviation in the surface color of the magnet were also 27 performed as these were seen to be indicative of issues with magnetic performance. In this case, we suggest that it would require a specific incentive from within the firm to upgrade skills, if it is not externally induced, such as in the case explored here. 
1 In the conceptual development rounds, the communication and articulation between the participants draws on specific in-house manufacturing knowledge, which is not codified and leads, in its final rounds, to the specification of how the magnet is to function in a system module, e.g. a motor. This again highlights the role of codification and its implications for deskilling. The functions are codified in form of technical specifications that are to be achieved, namely tolerances and magnet properties (rather than magnet look or material). This codification then enables a transmission by the T1-supplier of the automotive industry to the magnet manufacturer.

Importantly, codification does not prescribe details of the manufacturing process but rather the characteristics of the output to be achieved. Thus, the manufacturing process itself remains uncodified and reliant on both the articulation and the sharing of experiences, imitation, performance and thus, tacit knowledge (Polanyi, 1966). This explains the relatively advantageous positioning of the European manufacturer compared to the Chinese manufacturer: the European firm not only possesses the advanced magnet manufacturing technology which allows for flexibility in the magnet shape that can be achieved, and thus flexibility in how to approach a desired output (of tolerances and properties), but also particular process- and material-related tacit knowledge. A manufacturer makes explicit reference to and distinguishes between codification and know-how in magnet manufacturing: “(...) it is a very, very specific and to some extent also non-codified know-how which cannot be studied or looked up in books (C1d)."

This knowledge includes insights on the behaviour of magnet material in particular shapes into which the magnet material is injected, and therefore European manufacturers with injection-bonding technology were invited by $\mathrm{T} 1$ firms to participate in collaborative workshops in which magnet designs are discussed. Here, the feasibility of certain technical specifications is discussed as the manufacturer articulates particular information that draws on in-house manufacturing knowledge related to magnet material processing (compounding) and magnet manufacturing (injection-bonding) experience. The articulation and sharing of information based on experiences from magnet manufacturing that the representatives of the magnet manufacturer bring to the collaborative exchanges with the T1-supplier and the car manufacturer are important for the design of future 
1 into the design file for a magnet. For the T2 magnet manufacturer, the advantage of participating in these meetings rests with staying up to date on recent technological developments and considerations, in addition to heightened chances of being awarded a supply contract due to prior participation in the design stage.

\section{$5 \quad$ 4.4 Transmission of codified specifications in design files for simple magnets}

6 European suppliers describe the outsourcing of the compression-bonded manufacturing to their Chinese suppliers as being made possible due to codified information that is easily transmissible in design files with technical specifications. The Chinese manufacturer can deliver low-priced compression-bonded magnets, and thereby enables the T2 European manufacturer, who has supply ties with the T1-buyer, to be a one-stop-shop supplier. Impediments such as insufficient language skills of the chief engineering staff of the Chinese supplier, together with a lack in design skills, further promote the strategy of outsourcing particular, more easily codifiable manufacturing processes by the European suppliers to the automotive industry. One European magnet supplier described these aspects as follows: "The Chinese are not very good in design. Most of their strategy focuses on low cost and magnetic properties (W1b)."

Another European-based magnet manufacturer highlighted a further reason for the focus on the outsourcing of simple magnets: "There is very little secrecy [in China], which is one of the reasons [why] those of us who have JVs [joint ventures] $]^{3}$ in China, (...) are very, very circumspect about what technology we put into China because our assumption is if I teach my JV how to do it I might as well take out an ad in the South China Morning Post and tell everyone - including my European competitors (Cla)." This arguably reveals an intentional, strategic component to outsourcing, which is tied to information flows and codification.

We argue that as a consequence, deskilling of labour at the Chinese manufacturer occurs because the labour force is limited to the execution stage of manufacturing compressionbonded magnets with less sophisticated technology, a task distant to the collaborative conceptual design in which the T2 manufacturer can engage. It appears that a

\footnotetext{
${ }^{3} \mathrm{~A}$ joint venture is a business operation involving at least two firms, each of which retains their identity under a shared ownership. This shared ownership and executive power emerges from the different shares held by each firm of the joint venture, which decides over their executive rights, such as on directions of the JV.
} 
1 combination of factors, primarily confidence in the skills of the T3 supplier and concerns about the confidentiality of information and thus technology, contribute to - at best maintaining the T3 labour force at their current skill-levels.

\subsection{Non-codifiable service provision}

Several services are also provided in the one-stop-shop offer by the European manufacturer, which are all tied to knowledge-intensive tasks such as the manufacturing of management systems and the detection of defects: Human labor is needed for sorting the magnets if, for instance, the automated vision system in the production line has partially stopped working and cannot verify the quality of the magnets. This process is mostly carried out by the Chinese manufacturers. Besides the manual sorting processes, a knowledge-based labor component is effectuated at the European manufacturer in testing magnet quality:

“(...) we secure the magnet quality for them [the buyers] because this is something very few people know about. You know (...) the most important issue with the magnets Is the magnetic field...the magnet performance...you can never see, you can never look at the magnets to tell if this is a good magnet or if this is a bad magnet or if it even is the correct magnet material. (...) You need to have the test equipment and you need to have the knowledge. And that we provide to them and that's the reason, we can add some money to the unit price and they [the buyers] are willing to pay for it (N2b)."

Following on from manufacturing and quality control, the assembly of magnets was integrated in-house, as it is considered to be a service that requires particular knowledge and skills, both of which are already present at the European magnet manufacturer and offered in the package one-stop-shop solution: "We have got the skills in magnetizing technology, assembly technology and handling technology. So, we use those skills to produce a sub-assembly (...) which will save the customer time and effort in putting it together (C1d).,

In this section, we have shown how codification enables European magnet manufacturers to position themselves advantageously in the global automotive value chain, compared to Chinese magnet manufacturers. We argued that their tacit knowledge acquired through 
1 learning-by-doing, the so-called experiential dimension of tacit knowledge (Polanyi

2 1966), enables them, through the combination of integrated processes tied to magnet manufacturing, and collaborative design with their buyers, to focus on the conceptual stages of magnet design. This represents a form of upskilling the European labor force while outsourcing the execution of less sophisticated manufacturing tasks to Chinese suppliers, resulting in (relative) deskilling of the Chinese labor force. In addition, codification and tacit knowledge (both in its experiential and cognitive dimension), appear to provide decisive demarcations for geographically 'fixing processes of upskilling and deskilling, firstly, by outsourcing less sophisticated manufacturing methods, and secondly, by creating the potential to further automate these methods in the future.

\section{Conclusions}

In this paper, we have aimed to demonstrate the continued relevance of Braverman's deskilling thesis in contemporary capitalism. High-tech value chains are of course not immune to the pressures of cutting labor cost and we have argued that the differential roles of codification and tacit knowledge are crucial to understand deskilling in the context of value chain development and efforts for social and economic upgrading. To substantiate our discussion of the potency of codification for deskilling, we have explored whether and how the Chinese manufacturers as suppliers of components in automotive GVCs are impeded by the geographical division of labor into complex and creative conceptual work and rather simple execution tasks, a major aspect in the deskilling debate. This is manifested in the preference of European magnet manufacturers to integrate processes that are considered key to the manufacturing of advanced magnets, rather than patenting (and thus, codifying) these.

While Chinese manufacturers are able to technologically develop their processes through learning-by-doing, the experiential dimension of tacit knowledge is tied to the investment of time and labor. Industrial upgrading on a national scale may well be observed over time, yet to date has been limited, as we have shown. What is more, the effects for the type of labor required are variegated and in many instances will not lead to the desired social upgrading and skills development necessary for sustained socio-economic development and employment: For instance, instead of operating soft-pressing processes, automation might change the activities of labor to monitoring machines. Yet, as this is 
1 occurring over time, technological development is also progressing at the European manufacturers' sites, and thus demonstrating the potential to reproduce existing spatial divisions of labor between more creative and routine tasks, with implications for deskilling in 'high-tech' manufacturing.

Some information flows are constrained within particular exchanges, such as those in which T2 suppliers in the automotive industry participate: conceptual design rounds where they contribute by articulating their tacit knowledge. The information flows in these exchanges, as we have argued, ultimately place the European magnet manufacturer in a stronger GVC position, as the focus on conceptual design of magnets, together with the sophisticated manufacturing method of injection-bonding, allows for upskilling of their labor force. Simultaneously, other information flows by the European manufacturer trigger (relative) deskilling elsewhere, as the manufacturing activity of Chinese suppliers is maintained at the more simplistic, laborious compression (soft-pressing) bonding method. This in turn, as we demonstrated, leaves the Chinese supplier with a limited, less sophisticated product portfolio that can be manufactured without the articulation of further information by the European firm: Information is transmitted in design files that contain the technical specifications. That codified information may also be widely distributed, maintaining labor in China in roles distant to the state-of-the art technological development.

Specifically, we analyzed how such codification decisions liberate some workers in some places for skills upgrading (upskilling), and limit others to repetitive routine tasks geographically and relationally distant from innovative collaboration, or (relative) deskilling. The integration of particular processing segments prior to the actual manufacturing of the magnets by the European magnet manufacturer further reinforces this spatial division in labor, as the experiential dimension of the tacit knowledge is further strengthened by improving already sophisticated processes that enable to widen knowledge on magnet material handling, and compounding.

With the empirical case developed here, we have illustrated the significance of examining codification and tacit knowledge as a crucial determinant of the international division of labor and the ongoing transformation of work and deskilling in GVCs. Focusing on codification sheds light on information flows and non-codified articulations of knowledge 
that tap into the experiential and cognitive dimensions of tacit knowledge, which consequently separate labor into forms that on the one hand execute a narrow range of routine manufacturing tasks, while on the other hand freeing up other workers to engage in conceptual and creative tasks such as design. This research has implications for the study of labor and social upgrading. As firms and regions aim for economic upgrading towards what is (often problematically) called the new 'knowledge economy', they are also faced with the threats of automation and a growing precariousness of work. Closer attention to skills development or the lack thereof in studies of social upgrading - in addition to wages, working conditions and labor rights - therefore is important for a fuller appreciation of the future of work in and beyond GVCs and GPNs.

\section{References}

Barboza, D. and Tabuchi, H. 2010. Power grows for striking Chinese workers. New York Times, 8 June, p. B1.

Barrientos, S., Gereffi, G. Rossi, A. 2010. Economic and Social Upgrading in Global Production Networks: Developing a Framework for Analysis. Capturing the Gains Working Paper 3.

Barrientos, S., Gereffi, G. and Rossi, A. 2012. Economic and Social Upgrading in Global Production Networks: A New Paradigm for a Changing World. International Labour Review 150 (3-4), 319-40.

Braverman, H., 1974. Labor and Monopoly Capital. Monthly Review Press, New York.

Coe, N.M. and Hess, M. 2012. The Geographies of Production. In: Barnes, T., Peck, J. and Sheppard, E. (eds.), The Wiley-Blackwell Companion to Economic Geography. Wiley-Blackwell, Malden/Oxford, 153-165.

Coe, N.M. and Jordhus-Lier, D.C. 2010. Re-embedding the Agency of Labour. In: Knutsen, H.M., Bergene, A.C. and Endersen, S.B. (Eds.) Missing Links in Labour Geographies. Ashgate, Aldershot.

Coe, N.M. and Yeung, H.W.-C. 2015. Global Production Networks. Theorizing economic development in an interconnected world. Oxford University Press, Oxford.

Froebel, F., Heinrichs, J. and Kreye, O. 1981. The New International Division of Labour. Cambridge: Cambridge University Press.

Gereffi, G. and Lee, J. 2012. Why the world suddenly cares about global supply chains. Journal of Supply Chain Management 48 (3), 24-32.

Gereffi, G. 2009. Development models and industrial upgrading in China and Mexico. European Sociological Review 25 (1), 37-51.

Gereffi, G., Humphrey, J. and Sturgeon, T. 2005. The governance of global value chains. Review of International Political Economy 12, 78-104. 
Gereffi, G., Humphrey, J., Kaplinsky, R. and Sturgeon, T.J. 2001. Introduction: Globalisation, Value Chains and Development. IDS Bulletin 32, No. 3.

Gereffi, G. and Korzeniewicz, M. 1994. Commodity Chains and Global Capitalism. Praeger, Westport, CT.

Gertler, M. 2003. Tacit knowledge and the economic geography of context, or the undefinable tacitness of being (there). Journal of Economic Geography 3, 75-99.

Gibbon, P. and Ponte, S. 2005. Trading Down. Africa, Value Chains, and the Global Economy. Temple University Press.

Henderson, J., Dicken, P., Hess, M., Coe, N.M. and Yeung, H.W-C., 2002. Global production networks and the analysis of economic development. Review of International Political Economy 9, 436-64.

Hopkins T. and Wallerstein I., 1977. Patterns of development of the modern worldsystem. Review 1, 11-145.

Humphrey, J. 2004. Upgrading in global value chains. Policy Integration Department, Working Paper No. 28. ILO, Geneva.

Humphrey, J. and Schmitz, H. 2002. How does insertion in global value chains affect upgrading in industrial clusters? Regional Studies 36 (9), 1017-1027.

Jha, P. and Chakraborty, A. 2014. Post-Fordism, Global Production Networks and Implications for Labour. Institute for Studies in Industrial Development, Working Paper 172, New Delhi.

Knorringa, P. and Pegler, L. 2006. Globalisation, firm upgrading and impacts on labour. Tijdschrift voor Economische en Sociale Geografie 97 (5), 470-479.

Lee, J., Gereffi, G. and Barrientos, S. 2011. Global Value Chains, Upgrading and Poverty Reduction. Capturing the Gains Briefing Note No. 3, November.

Lipietz, A. 1985. Fordisme, fordisme peripherique et metropolisation [Fordism, peripheral fordism, and metropolitanization]. CEPREMAP, Working Paper 8514, Paris.

Massey, D. 1984. Spatial Divisions of Labour: Social Structures and Geography of Production. Second ed. (1995). Routledge, New York.

Milberg, W. and Winkler, D. 2011. Economic and social upgrading in global production networks: Problems of theory and measurement. International Labour Review 150 3-4, 341-365.

Peck, J. 2017. Offshore. Exploring the Worlds of Global Outsourcing. Oxford University Press, Oxford.

Pietrobelli, C. and Rabellotti, R. 2006. Clusters and value chains in Latin America: In search of an integrated approach. In C. Pietrobelli and R. Rabellotti (Eds.) Upgrading to compete: Global value chains, clusters and SMEs in Latin America. Inter-American Development Bank, Washington D.C., 1-40.

Pipkin, S. 2011. Local means in value chain ends: dynamics of product and social upgrading in apparel manufacturing in Guatemala and Colombia. World Development 39, 2119-2131. 
Polanyi, M. 1966. The tacit dimension. The University of Chicago Press, Chicago and London.

Previtali, F.S. and Fagiani C.C. 2015. Deskilling and degradation of labour in contemporary capitalism: the continuing relevance of Braverman. Work Organisation, Labour \& Globalisation 9, 76-91.

Robertson, R.N. and Langlois, R.N. 1995. Innovation, networks, and vertical integration. Research Policy 24, 543-562.

Rossi, A. 2011. Economic and social upgrading in global production networks: the case of the garment industry in Morocco. PhD thesis. Institute of Development Studies, University of Sussex, Brighton, UK, 1-236.

Selwyn, B. 2011. Beyond firm-centrism: re-integrating labour and capitalism into global commodity chain analysis. Journal of Economic Geography 12, 205-226.

Selwyn, B. 2013. Social Upgrading and Labour in Global Production Networks: A Critique and an Alternative Competition \& Change 17(1), 75-90.

Streeck, W., 2005. The Sociology of Labor Markets and Trade Unions. In Smelser N.J. and Swedberg R. (Eds.) The Handbook of Economic Sociology. Princeton University Press, Princeton and Oxford, pp. 254-83.

Sturgeon, T.J. 2002. Modular production networks: A new American model of industrial organization. Working Paper Series. Industrial Performance Center. Massachusetts Institute of Technology.

Schilling, M.A. and Steensma, H.K. 2001. The Use of Modular Organizational Forms: An Industry-Level Analysis. The Academy of Management Journal 44 (6), 1149-1168.

Schoenberger, E. 1988. Multinational Corporations and the New International Division of Labor: A Critical Appraisal. International Regional Science Review, Vol. 11, No. 2, 105-119.

Sørensen, A.B., 1994. Firms, Wages, and Incentives. In Smelser N.J. and Swedberg R. (Eds.) The Handbook of Economic Sociology. Princeton University Press, Princeton and Oxford, pp. 504-28.

Starosta, G. 2016. Revisting the New International Division of Labour Thesis. In: Charnock, G. and Starosta, G. (eds.) The New International Divison of Labour. Global Transformation and Uneven Development. Palgrave Macmillan, London, 79-103.

Tokatli, N. 2013. Toward a better understanding of the apparel industry: a critique of the upgrading literature. Journal of Economic Geography 13, 993-1011.

Whittaker, H., 1990. Managing Innovation: A study of British and Japanese factories. Cambridge University Press, Cambridge.

Williamson, O.E. 1981. The Economics of Organization: The Transaction Cost Approach. American Journal of Sociology 87 (3), 548-540.

Williamson, O.E. 1983. Credible Commitments: Using Hostages to Support Exchange. The American Economic Review 73 (4), 519-540.

Zeng, D.Z. 2010. Building engines for growth and competitiveness in China: Experience with special economic zones and industrial clusters. World Bank, Washington D.C. 
1 Zuboff, S. 1988. In the age of the smart machine: the future of work and power. 2 Heinemann, Oxford. 